\title{
Anatomical Features of Vibrio fetus: Electron Microscopic Survey
}

\author{
By A. E. RITCHIE, R. F. KEELER AND J. H. BRYNER \\ National Animal Disease Laboratory, Agricultural Research Service \\ Animal Disease and Parasite Research Division, U.S. Department of Agriculture, \\ Ames, Iowa, U.S.A.
}

(Received 2 November 1965)

\section{SUMMARY}

Vibrio fetus was examined in shadow-cast, negative-contrast and thinsectioned preparations. Four morphological types were noted in shadowed specimens: comma, coccoid, S-shaped and filamentous. In negative-contrast preparations organisms were differentiated into two types on the appearance of their cytoplasmic mass. A large spherical cytoplasmic inclusion was frequently evident at the flagellated pole of freshly harvested organisms. Various morphological variants, 'sports', e.g. multiflagellate, were easily detected. A non-motile isolate was either devoid of flagella or exhibited only a short stub at the pole.

In thin-section preparations anatomical features noted were: a rugose loosely fitting membranous integument; a complex cytoplasmic membrane of honeycomb-like structure; a fibrillar nucleoplasm and fibrillar cytoplasmic ground substance with associated ribosomes; lamellated or cytoplasmic granules bounded by a smooth membrane. At the flagellated pole the cytoplasmic ground substance was generally rarefied and a coneshaped flagellar basal granule was present. The flagella were enlarged at their proximal terminus. Mesosome-like elaborations of the cytoplasmic membrane were not observed. It was concluded that Vibrio fetus closely resembles members of the genus Spirillum.

\section{INTRODUCTION}

Infection of the reproductive tract of domestic animals, especially in the bovine and ovine species, is frequently caused by Vibrio fetus. Its general morphological characteristics were carefully described by Smith \& Taylor (1919) who noted a striking similarity to the spirilla. Their classification of this Gram-negative organism within the genus Vibrio was based upon the observation that it 'assumes the comma form in its early, most active stage of multiplication in cultures and has single polar flagella'. Smith \& Taylor (1919) distinguished four types of organisms differing in their shape: (1) comma-shaped organisms with a single polar flagellum; (2) S-shaped organisms which were bipolarly flagellate; (3) coccoid organisms, generally with a single flagellum; (4) filamentous organisms in which no segmentation was discerned. Multitrichous organisms were common and occasionally filamentous organisms were seen with several short lateral flagella in addition to the terminal ones. These morphological characteristics, with the exception of multiple polar or lateral flagella, were confirmed by electron microscopic observations of shadow-cast preparations by Rhoades (1954). 
Studies of the 'cyto-architecture' of Vibrio fetus were initiated by Werner, Levy \& Spurlock (1961) with application of thin-sectioning techniques to methacrylateembedded organisms. They described the organism as consisting of: (1) an external 'capsular residue', (2) a 'single delicate delimiting' cell membrane, (3) a finely granular cytoplasm, (4) one or more large cytoplasmic granules of high electronscattering power, presumably 'polyphosphates', (5) an electron-lucid region within the cytoplasm assumed to be the bacterial nucleus. Subsequent investigations by Werner (1963) with epoxy-embedded organisms indicated that the 'single delicate delimiting' cell membrane was more likely to be a double-layered structure and that the cytoplasm appeared fibrillar, rather than 'finely granular' as seen in the methacrylate-embedded specimens. These differences were attributed to the different embedding matrices used.

The aim of the present investigation was to gain a more detailed understanding of the anatomical features of Vibrio fetus as a prelude to isolation and characterization of its immunogenic antigens; the accompanying paper (Keeler, Ritchie, Bryner \& Elmore, 1966) describes the preparation and properties of some subcellular components, namely, flagella and 'cell-wall' material. Some preliminary results were communicated to the Twenty-second Annual Meeting of the Electron Microscopy Society of America (Ritchie, Bryner \& Keeler, 1964).

\section{METHODS}

Preparation of organisms. Several isolates of Vibrio fetus, characterized in earlier dissociation studies, were grown at $37^{\circ}$ on Albimi agar containing thioglycollate and gluthathione by the method of Bryner, Frank \& O'Berry (1962). Organisms were usually harvested by flushing the agar surface of 48- to 72-hr cultures with the phosphate buffered saline (PBS) of Dulbecco \& Vogt (1954). Occasionally distilled water or a negative-contrast medium was used for the initial suspension. Organisms not examined directly after harvesting were washed thrice with PBS or distilled water and stored at $-\mathbf{2 0} 0^{\circ}$. For some observations, organisms subjected to a shortterm ( 3 min.) treatment in the Mickle machine were used.

Electron microscope preparation techniques. Organisms were prepared by the following methods: palladium-metal shadowing; negative-staining with phosphotungstate or uranyl acetate; thin sectioning of divinylbenzene cross-linked methacrylateembedded specimens.

Phosphotungstic acid adjusted to $\mathrm{pH} 7 \cdot 2$ was most frequently used as the negative-staining medium; it was prepared according to Brenner \& Horne (1959). Uranyl acetate (van Bruggen, Wiebenga \& Gruber, 1960) was used at $1 \%(\mathrm{w} / \mathrm{v})$ in the final sample suspension; a trace of bovine serum albumin was added to enhance spreading. Grid mounts were made on carbon-coated collodion-filmed substrates by two methods: the frozen-sectioning technique of Almeida \& Howatson (1963) and the loop-film procedure described by Murray (1963).

Thin-sectioned specimens were prepared by a combination of methods previously described by others (Kellenberger, Ryter \& Séchaud, 1958b; Kushida, 1961; Murray \& Birch-Andersen, 1963). Organisms were harvested in PBS; 'pre-fixed' for 30 min. by addition of $2 \%(w / v)$ unbuffered $\mathrm{OsO}_{4}$ to a concentration of $\mathbf{0 . 2 5} \%$ $(\mathrm{w} / \mathrm{v})$; pelleted by centrifugation and resuspended in a drop of warm liquid agar 
$(1-2 \%, w / v)$ at $50-55^{\circ}$. After solidification, the agar suspension of organisms was minced at room temperature $\left(25^{\circ}\right)$ in the veronal-buffered osmium tetroxide fixative of Kellenberger et al. $(1958 b)$ containing $1 \%(\mathrm{w} / \mathrm{v}) \mathrm{OsO}_{4}$ and $0.01 \mathrm{M}-\mathrm{Ca}^{2+}$. The agar cubes were transferred to fresh fixative for further fixation overnight at $4^{\circ}$. After fixation, the agar cubes were transferred to aqueous uranyl acetate (saturated solution) for $2 \mathrm{hr}$ at room temperature before dehydration which was accomplished through an ethanol series beginning at $50 \%(\mathrm{v} / \mathrm{v})$ ethanol in water. Embedding was done in butyl- + methyl- $(85+15$, by vol.) methacrylate with divinylbenzene (divinylbenzene 55 kindly supplied by Dow Chemical Company, Midland, Michigan, U.S.A.) added $(5 \%, v / v)$. Sections were obtained with a diamond knife on the LKB Ultratome (LKB Instruments Inc. Rockville, Maryland, U.S.A.), and post-stained with alkalinized lead solution. The lead-staining solutions were prepared according to Karnovsky (1961) or Millonig (1961).

Palladium-shadowed specimens were photographed in an RCA EMU-3F electron microscope. All other micrographs were taken in a Phillips EM-200 electron microscope operated with double condenser illumination.

\section{RESULTS}

\section{Palladium-shadowed organisms}

Organisms of all strains examined were generally similar in morphology. Coccoid and filamentous organisms were only infrequently observed. The appearance of the organisms was essentially the same as reported by Rhoades (1954). A smooth contoured envelope bounded the organism; the cytoplasm was wrinkled and a slight hump was frequently observed in the region on flagellar insertion. A typical field is illustrated in Pl. 1, fig. 1. Comma-shaped organisms had a single flagellum at one pole, whereas S-shaped organisms frequently had a flagellum at each pole. Freelying flagella were occasionally observed near S-shaped organisms and may have been released by mechanical stress during preparation. One end of such a free-lying flagellum was usually bent or hooked.

\section{Negative-contrast mounted organisms}

Organisms examined in either phosphotungstate or uranyl acetate negativestaining media were comparable in appearance; however, uranyl acetate appeared to produce a more coarsely grained matrix about the specimens and was not much used. In contrast to metal-shadowed preparations, organisms mounted in negativestaining media were of two general types distinguished by the appearance of their cytoplasmic contents. The most commonly observed type displayed pronounced cytoplasmic retraction and clumping; the organisms of the less frequently encountered type appeared to be turgid and their cytoplasmic mass was marked by distinct transverse clefts and small random fissures. These two types are illustrated in the field shown in Pl. 1, fig. 2, and are reminiscent of the 'secondary' and 'primary' forms of Piekarski (1937, 1939). No relationship between our two observed types and the state of their nuclear apparatus was established by the techniques used.

Various atypical organisms or 'sports' were easily recognized in the negativecontrast preparations. These included organisms bearing unusually long (Pl. 2, 
fig. 3) or multiple flagella (Pl. 2, figs. 4, 5). The incidence of 'sports' was low and for multiflagellate organisms, the maximum number of flagella observed at a single pole was five. Multiflagellate organisms were generally four to six times the length of a typical curved rod, i.e. 5-10 $\mu$. On two occasions, elongated organisms were observed which showed flagella at non-polar regions. The positions of emergence were at multiple lengths of a typical S-shaped organism from the poles. No segmentation was noted in the areas where these lateral flagella arose.

Evidence for the independence of flagella observed in multiflagellate 'sports' was sought from organisms subjected to rupture and lysis (freezing and thawing in distilled water, and mechanical breakage). In Pl. 2, fig. 6, the terminal region of a lysed organism bearing two flagella is illustrated, one flagellum is attached to the retracted cytoplasmic mass and the other to the envelope. Organisms mildly disintegrated in the Mickle apparatus (3 min.) frequently exhibited separate attachment granules for each flagellum. These granules measured about $50 \mathrm{~m} \mu$ maximum diameter and are illustrated in Pl. 2, fig. 7 .

Some isolates of Vibrio fetus lose their motility when maintained in laboratory culture. Organisms of one such culture were examined to determine whether any gross morphological alteration had accompanied loss of motility. Plate 3, fig. 8, illustrates the result. Organisms with a retracted and clumped cytoplasmic mass showed no evidence of flagella, and only occasionally could one note a dimple in a polar region. Turgid organisms exhibited a $50-60 \mathrm{~m} \mu$ flagellar stub at the pole. Free-lying flagella or flagellar fragments were not observed in these preparations.

Some information about the organization of the cytoplasmic contents of intact organisms was obtained from the negative-contrast preparations. Most interesting was the frequent occurrence of a single large spherical body in the vicinity of the flagellated pole. These bodies had a homogeneous appearance with diameters of $0 \cdot 1-0 \cdot 4 \mu$; they are illustrated in Pl. 3, fig. 9, 10. Similar bodies were not observed at the unflagellated end of the organism which was typically flattened and less marked by clefts or fissures than the remainder of the cytoplasm.

Although several species of micro-organisms exhibit intracytoplasmic membranous elements (mesosomes, plasmalemmasomes, etc.) when examined in negative-contrast media (see, for example, Zwillenberg, 1964), no such elements were detected in Vibrio fetus.

Anatomical features of the integument and internal membrane system were obscured by the thickness of the intact organisms. Details of these structures were sought in preparations of organisms subjected to freezing and thawing. Under these conditions, many organisms ruptured and released their cytoplasmic contents. The cellular residues retained their characteristic curvature and two membranous sacs were regularly recognized. Plate 4, fig. 11, illustrates the appearance of the residue of an S-shaped organism. The two membranous elements are readily apparent: the envelope and a smaller inner coarsely matted sac. This envelope bears evidence of its bipolar flagella. One pole (left) displays a flagellar stub, whereas at the opposite pole only an orifice in the integument is noted. No regular geometrical pattern similar to the macromolecular complex of the 'cell-wall' of Spirillum sp. (Houwink, 1953), or S. serpens (Murray, 1963) was observed in the envelope of Vibrio fetus in our preparations.

Free-lying flagella were rarely observed in negative-contrast preparations of 
freshly harvested organisms. The flagellar fine structure of freshly harvested organisms was most generally obscured by adhering electron-dense material. A discussion of this problem as encountered with flagella of Salmonella typhimurium was given by Kerridge, Horne \& Glauert (1962). Frozen and thawed preparations of distilled water suspensions of Vibrio fetus contained numerous free-lying flagella. Contamination of the flagellar surface with adsorbed electron-dense material was minimal but evident. A typical intact flagellum still associated with the membranous covering of its attachment granule is illustrated in Pl. 4, fig. 12. No evidence of a sheath was observed in either negatively stained or thin-sectioned preparations such as reported in Vibrio metchnikovii (Gordon \& Follett, 1962; Glauert, Kerridge \& Horne, 1963). High magnification examination of flagella in the frozen and thawed preparations suggested that they were of a parallel-stranded design. An enlargement of the central portion of the flagellum shown in Pl. 4, fig. 12, is shown in Pl. 4, fig. 14, and illustrates its parallel-stranded appearance. The maximum number of longitudinal lines observed was four. A central hole was not evident except at the distal end of the flagellum. Measurement of this terminal core indicated a diameter of about $3 \mathrm{~m} \mu$. The ends of fractured flagella were jagged and rough, and exhibited no tendency to unravel or to splay out into elementary strands. This feature is illustrated in Pl. 4, fig. 13, and suggests that the elementary strands are probably interconnected.

\section{Thin-sectioned specimens}

Vibrio fetus organisms maintained their characteristic curvature after embedding. Their general appearance could only be determined from nearly longitudinal profiles. Under these conditions, three types were distinguishable; they are represented in Pl. 5, figs. 15, 16, and Pl. 6, fig. 17. A dividing S-shaped organism is illustrated in Pl. 5, fig. 15, while PI. 5, fig. 16 represents an S-shaped organism which shows no obvious signs of division. Somewhat more than one-half of a typical comma-shaped organism is shown in Pl. 6, fig. 17; this organism closely resembles one of the daughters seen in Pl. 5, fig. 15.

Integument. A rugose loosely disposed membrane enveloped the organism. This structure is commonly referred to as the 'cell-wall', although Werner et al. (1961) and Werner (1963) preferred the term 'capsular residue'. It was not closely applied to the main body of the organism except over the flagellated pole. In thick sections, it was generally broad and diffuse but frequently appeared multilaminate. In thinner sections and accurate transection, it appeared as a single composite membrane consisting of two osmophilic layers about $30 \AA$ thick separated by a less dense $40 \AA$ zone. A comparison of these profiles is illustrated in Pl. 5, figs. 15a, 16a, which are enlargements of portions of figs. 15 and 16, respectively. Also illustrated in Pl. 5, figs. 16, $16 a$, are curious small $(30-50 \mathrm{~m} \mu)$ globular or looped formations present in this superficial membrane. The exterior surface of the 'cell-wall' was conspicuously clean, presumably as the result of 'early enrobing' in agar, as suggested by Murray \& Birch-Andersen (1963). No homogeneous layer or 'gap substance' (Robertson, 1959) was detected lying between this superficial membrane and the main body of the organism. Electron scattering was frequently observed in this space. However, close examination of the micrographs suggested that this could be attributed to tangential sectioning through the contour of the enveloping membrane. 
Cytoplasmic membrane. In contrast to the wavy 'cell-wall', the membrane which limited the protoplasmic mass was typically smooth and taut, and exhibited no pronounced invaginations or enfoldings. This membrane was similar to the integument in dimensions and electron-scattering properties, but with additional elaboration as described below. Plate 5, figs. 16, 16 $a$, illustrate this resemblance between the two triple-layered structures. Immediately underlying this composite membrane we frequently observed segments of a highly ordered array of short bar-like profiles with centre-to-centre spacings of about 60-80 $\AA$. These arrays were particularly conspicuous at the flagellated pole. The localization of these elements in Vibrio fetus was not restricted to the flagellated pole. Similar profiles were regularly observed elsewhere as illustrated in Pl. 5, fig. 15, and Pl. 6, fig. 17. In Pl. 5, fig. 15, short segments of these profiles may be seen in the constricted region separating the sister organisms as well as at the flagellated poles. When viewed in transverse section, this array was seen to circumscribe the entire cytoplasm, as illustrated in Pl. 6, fig. 18. The thin bar-like elements of this array were oriented perpendicular to the composite overlying membrane and appeared to arise from it. Our techniques were inadequate to establish unreservedly a true intercalation. The centripetal termini of these bar-like elements fell on a line situated about $200 \AA$ inside the cell body, forming a fused osmophilic boundary demarcating the array from adjacent cytoplasmic mass. This inner boundary was more diffuse and generally thicker than the adjoining osmophilic layer of the composite membrane. This diffusedness gave it a finely scalloped appearance as can be noted in Pl. 6, fig. 18. Since similar profiles of this structure were observed in both transverse and longitudinal section, we interpret the geometrical form of this complex to be a layer of radially oriented compartments arranged in a honeycomb-like network. The intricate arrangement of these structural elements and their intimate association with the overlying composite membrane make it difficult to assign an accurate terminology to this complex. The terms 'polar membrane' (Murray \& Birch-Andersen, 1963) or 'polar cap' (Cohen-Bazire \& Kunisawa, 1963) as used for similar structures in Spirillum serpens or Rhodospirillum rubrum appear to be precluded since this structure is not restricted to polar regions. Recently, Hickman \& Frenkel $(1965 b)$ have confirmed its presence in $R$. rubrum and reported a similar structure in $R$. molischianum (Hickman \& Frenkel, 1965 a). We have chosen to use the term complex cytoplasmic membrane to denote the entire complex consisting of the triple-layered membrane and its associated assemblage of these short centripetally-oriented compartments.

Cytoplasm and nucleoplasm. The cytoplasmic mass of Vibrio fetus was generally characterized as a compact fibrillar network. Small electron-dense patches were frequently associated with this network and may correspond to ribosomal elements. These components and their relationship to the fibrillar network are illustrated in Pl. 5, fig. 16a. In the flagellated polar region the cytoplasmic mass was markedly less compact than the typical ground substance. This rarefied space displayed no membranous interior boundary and its shape seemed to be determined by the presence of the surrounding cytoplasm. A cup-like profile was most frequently observed; it is illustrated in Pl. 5, fig. 15 $a$ and Pl. 6, fig. 17. A bell-shaped profile can also be noted in one of the organisms illustrated in Pl. 5, fig. 15 (at right). Of special concern to us was the possibility of observing in thin section the large spherical bodies detected in the flagellated polar region of intact organisms mounted 
in negative-contrast media (e.g. Pl. 3, figs. 9, 10). No obvious membrane-bounded profiles corresponding to these bodies were detected. Under the most favourable sectioning conditions we had the impression that a circular region was discernible, though barely, in the anticipated location. This region had dimensions comparable to those of the spherical bodies observed in negative-contrast preparations $(0 \cdot 1-$ $0 \cdot 4 \mu$ ). Its texture appeared somewhat more homogeneous than the adjacent cytoplasmic ground substance; this is illustrated in Pl. 5, fig. 15 $a$. It is possible that the cup-shaped profiles commonly encountered in thin sections of the rarefied cytoplasm at flagellated poles are a consequence of the interposition of these spherical bodies.

The nucleoplasm was typical of Gram-negative micro-organisms subjected to the fixation procedure of Kellenberger $e t$ al. $(\mathbf{1 9 5 8} b)$. It was generally centrally located and consisted of a loose random arrangement of very thin fibrils disposed in a space which exhibited negligible electron scatter (Pl. 5, figs. 15, 15 $a$; Pl. 6, fig. 17).

Cytoplasmic inclusions. Very dense granules measuring 500-800 A were observed in almost all organisms sectioned longitudinally. They were similar to the 'polyphosphate' granules previously reported in Vibrio fetus by Werner et al. (1961) but generally displayed a smooth membranous boundary. This feature is illustrated in the two granules of the organism shown in Pl. 6, fig. 17. Only occasionally were other inclusions observed; these other inclusions were best described as lamellar bodies and were larger than the dense granules noted above. One of these is illustrated in Pl. 5, figs. 16, 16a. The lamellar bodies were not observed in association with the complex cytoplasmic membrane.

Flagella and flagellar attachment. Flagella observed in longitudinal section were nominally $120 \AA$ in diameter except for their proximal end. Over a distance of 500-600 $\AA$, the proximal terminus was thickened to a diameter of about $170 \AA$. This widened region evidently corresponded to the flagellar stub (e.g. Pl. 5, fig. 15a). Plate 6, fig. 19, illustrates the proximal terminal region of a Vibrio fetus flagellum which displays this change in diameter. No significant fine structural details of the flagella were discerned in our thin-sectioned preparations. They did not appear unravelled or 'hollowed out' as noted by Forslind \& Swanbeck (1963) and Claus \& Roth (1964) with isolated flagella from Proteus vulgaris and Acetobacter suboxydans.

Flagellar attachment granules of triangular profile were frequently observed. Their presence was concomitant with: (1) a flagellar stub; (2) an obvious depression on the contour of the pole; (3) additional electron scattering in the space lying between the integument and the main body of the organism. These basal granules are illustrated in Pl. 5, fig. 15a, and Pl. 6, fig. 17. From their triangular profile it is clear that they are cone-shaped. Attachment of these basal granules to the complex cytoplasmic membrane or to the integument could not be discerned.

\section{DISCUSSION}

Application of the three complementary techniques of specimen examination revealed numerous anatomical details of Vibrio fetus. Its morphological characteristics as previously described by Smith \& Taylor (1919) and Rhoades (1954) were confirmed in our shadow-cast preparations.

Negative-staining of intact micro-organisms, introduced by Thornley \& Horne (1962), permitted easy detection of morphological variants. For multiflagellate 
organisms, the individual basal granules could only be demonstrated in a practical way by this technique. Compartmentalization and gross differentiation of the cytoplasm was discernible in most organisms because its orthographic projection was imaged by the electron optical system. Fine structural details of the intracellular environment could not be revealed because of superposition of images of the interposed mass.

Of the Gram-negative micro-organisms studied in the electron microscope, Spirillum serpens appears most closely to resemble Vibrio fetus. In thin section, both are commonly bounded by a compound wavy membrane or integument; have individual flagellar basal granules; frequently exhibit a rarefied cytoplasm at the flagellated pole; and their complex cytoplasmic membranes have similar profiles, including the unique centripetal compartmentalization. In addition, the singular large spherical body observed in negatively-stained $V$. fetus organisms is comparable to a structure noted in $S$. serpens and a Spirillum sp. by van Iterson (1947). These observations may further support the similarities between $V \cdot$ fetus and the spirilla recognized by Smith \& Taylor (1919) and recently emphasized by Leifson (1960).

Since the complex cytoplasmic membrane of two species of Rhodospirillum is similar to that of Vibrio fetus and Spirillum serpens, a taxonomic significance for this structure cannot be assumed. Although these micro-organisms possess widely different metabolic capabilities, they share a common morphological form, the curved rod. It is possible that the complex cytoplasmic membrane common to all three may contribute a torsional force at some stage of development and influence the conformation of the organism. It should be noted that the presence of such a highly ordered structure in the location commonly reserved for the bacterial cytoplasmic membrane does not support the view of Clarke \& Lilly (1962) that the surface layers of Gram-negative organisms 'consist of two "unit" membranes with a rigid layer in between'.

Schematic representations of a generalized concept of the 'cell-wall' of Gramnegative bacteria have been advanced in several recent reports (Claus \& Roth, 1964; Murray, Steed \& Elson, 1965; de Petris, 1965). Based upon electron microscopic observations, these reports focus attention on the location of the 'mucopolymer layer' and suggest that it lies exterior to, but in close apposition with, a triplelayered ('unit') cytoplasmic membrane. Claus \& Roth (1964) and Murray et al. (1965) based their assignment of a position for the 'mucopolymer layer' on the presence of electron-scattering substances lying immediately outside the cytoplasmic membrane, whereas de Petris based his location of the 'mucopolymer layer' on a narrow electron-transparent zone in this position. de Petris also noted (in Escherichia coli) a more peripheral-structured layer which 'in some instances-is composed of globular elements'.

The integument of Vibrio fetus was consistently rugose in appearance except over the flagellated pole; we believe that this is natural and not artificial. This interpretation is contrary to the assumption by Kellenberger \& Ryter (1958) that the wavy profile of the integument of Escherichia coli was an artifact arising from its detachment from the main protoplasmic body of the organism. If this were the case, one should be able to detect a 'gap substance' or perhaps some other evidence of bonding between the integument and the cytoplasmic membrane. No evidence of this sort was observed in our preparations of $V$. fetus although we could readily 
detect the presence of electron-dense material contributed by the flagellar basal granule in the space underlying the integument at an appropriate pole. The possibility cannot be excluded, however, that some labile bonding substance might have been removed during harvesting or the processes of fixation and embedding.

Weidel, Frank \& Leutgeb (1963) noted the susceptibility of the 'R-layer' ('mucopolymer') of Salmonella gallinarum to enzymic degradation. They suggested that to minimize autolysis one 'has to squirt the culture into boiling water immediately after stopping aeration'. Although the Vibrio fetus organisms used here were not subjected to such treatment, it seems reasonable to believe that the $\mathrm{OsO}_{4}$ fixation was sufficient to inhibit enzymic degradation, since the typical curvature of the organisms was preserved throughout the embedding and sectioning procedures.

The close association of the various membranous elements of bacteria is a serious impediment to the assignment of a structural or physiological role and to the physical separation necessary for chemical characterization. Partial lysis of Vibrio fetus by a single freeze and thaw cycle appears to separate the integument from the complex cytoplasmic membrane. This separation might account for our inability to detect a regular geometrical pattern similar to the macromolecular complex seen in the 'cell-wall' of Spirillum sp. (Houwink, 1953), S. serpens (Murray, 1963) and other Gram-negative organisms. Other explanations are, however, possible. We incline to the view that these previously observed macromolecular patterns might represent a complex cytoplasmic membrane alone or in association with the cell's integument.

The concept of functional integration of the bacterial cell-wall and plasma membrane was discussed by Mitchell \& Moyle (1946). This hypothesis seems attractive for Vibrio fetus. We have not been able to associate any one of the membranous elements of $V$. fetus with the role of maintaining cell shape (see, Keeler et al. 1966).

The highly electron-scattering granules within the cytoplasm of Vibrio fetus, first observed by Werner et al. (1961) have been found by us to be bounded by a membrane, but no functional significance of these granules or the larger lamellated bodies has been established in our work.

Takagi \& Asaki (1960) described in a water vibrio flagellar basal granules similar to those observed in Vibrio fetus. These authors also noted that the basal granules of detached flagella were irregularly bordered, suggesting an attachment to the cell's cytoplasmic membrane. It would be interesting to know whether this water vibrio has a structure corresponding to the complex cytoplasmic membrane of V.fetus.

The authors gratefully acknowledge the technical assistance of Mr W. Knaack in the preparation of the thin-section specimens and photographic enlargements. We thank Dr L. E. Roth (Department of Biochemistry and Biophysics, Iowa State University) for the use of the RCA EMU-3F electron microscope in the initial phases of this study. 


\section{REFERENCES}

Almeida, J. \& Howatson, A. F. (1963). A negative staining method for cell-associated virus. J. Cell. Biol. 16, 616.

Brenner, S. \& Horne, R. W. (1959). A negative staining method for high resolution electron microscopy of viruses. Biochim. biophys. Acta, 34, 103.

Bryner, J. H., Frank, A. H. \& O'Berry, P. A. (1962). Dissociation studies of vibrios from the bovine genital tract. Am. J. vet. Res. 23, 32.

ClARKe, P. H. \& Liluy, M. D. (1962). A general structure for cell walls of Gram-negative bacteria. Nature, Lond. 195, 516.

Claus, G. W. \& Rorh, L. E. (1964). Fine structure of the Gram-negative bacterium Acetobacter suboxydans. J. Cell Biol. 20, 217.

Cohen-Bazire, G. \& Kunisawa, R. (1963). The fine structure of Rhodospirillum rubrum. J. Cell. Biol. 16, 401.

DE Petris, S. (1965). Ultrastructure of the cell wall of Escherichia coli. J. Ultrastructure Res. 12, 247.

Dulbecco, R. \& Vogt, M. (1954). One-step growth curve of western equine encephalomyelitis virus on chicken embryo cells grown in vitro and analysis of virus yields from single cells. J. exp. Biol. 99, 183.

Fonslind, B. \& Swanbeck, G. (1963). The effect of osmium-fixation on bacterial flagella. Expl. Cell Res. 32, 179.

Glauert, A. M., Kerridge, D. \& Horne, R. W. (1963). The fine structure and mode of of attachment of the sheathed flagellum of Vibrio metchnikovii. J. Cell Biol. 18, 327.

Gordon, J. \& Follett, E. A. C. (1962). Differences in the sheath and core of vibrio flagella. Proc. 5th int. Congr. Electron Microscopy, 2, M-5.

Hickman, D. D. \& Frenkel, A. W. (1965 a). Observations on the structure of Rhodospirillum molischianum. J. Cell, Biol. 25, 261.

Hickman, D. D. \& Frenkel, A. W. $(1965 b)$. Observations on the structure of Rhodospirillum rubrum. J. Cell. Biol. 25, 279.

Houwink, A. L. (1953). A macromolecular monolayer in the cell wall of Spirillum sp. Biochim. biophys. Acta. 10, 360.

KARNovsky, M. J. (1961). Simple methods for "staining with lead' at high pH in electron microscopy. J. biophys. biochem. Cytol. 11, 729.

Keeler, F. R., Rrtchie, A. E., Bryner, J. H. \& Elmore, J. (1966). The preparation and characterization of cell walls and the preparation of flagella of Vibrio fetus. J. gen. Microbiol. 43, 439.

Kellenberger, E. \& Ryter, A. (1958). Cell wall and cytoplasmic membrane of Escherichia coli. J. biophys. biochem. Cytol. 4, 323.

Kellenberger, E., RYTer, A. \& Sḱchaud, J. (1958). Electron microscope study of DNA-containing plasms. II. Vegetative and mature phage DNA as compared with normal bacterial nucleoids in different physiological states. J. biophys. biochem. Cytol. 4, 671 .

Kerridge, D., Horne, R. W. \& Glauert, A. M. (1962). Structural components of flagella from Salmonella typhimurium. J. mol. Biol. 4, 227.

Kushida, H. (1961). A new embedding method for ultrathin sectioning using a methacrylate resin with three dimensional polymer structure. $J$. Electronmicroscopy $($ Tokyo $), 10,194$.

Leifson, E. (1960). Vibrio. Atlas of Bacterial Flagellation, ch. 19. p. 52. New York: Academic Press.

Milionig, G. (1961). A modified procedure for lead staining of thin sections. J. biophys. biochem. Cytol. 11, 736.

Mitcheld, P.\& Moyle, J. (1956). Osmotic function and structure in bacteria. In Bacterial Anatomy. Symp. Soc. gen. Microbiol. 6, 150.

Murray, R. G. E. (1963). On the cell wall structure of Spirillum serpens. Can. J. Microbiol. $9,381$.

Murray, R. G. E. \& Birch-Andersen, A. (1963). Specialized structure in the region of of the flagella tuft in Spirillum serpens. Can. J. Microbiol. 9, 393. 


\section{Electron microscopy of Vibrio fetus}

Murray, R. G. E., Steed, P. \& Elson, H. E. (1965). The location of the mucopeptide in sections of the cell wall of Escherichia coli and other Gram-negative bacteria. Can. J. Microbiol. 11, 547.

Piekarski, G. (1937). Zytologische untersuchungen an Paratyphus und Colibakterien. Arch. Mikrobiol. 8, 428.

Piekarski, G. (1939). Lichtoptische und ubermikroskopische untersuchungen zum problem des bakterienzellkerns. Zentbl. Bakt.ParasitKde (Abt. 1, Orig.), 144, 140.

RHOAdes, H. E. (1954). The illustration of the morphology of Vibrio fetus by electron microscopy. Am. J. Vet. Res. 15, 630.

Ritchie, A. E., Bryner, J. H., Jun. \& Keeler, R. F. (1964). Electron-microscopic anatomy of Vibrio fetus. Proc. 22nd Ann. Mtg. Elect. Microscope Soc. America, Abstr. B-43.

RoBertson, J. D. (1959). The ultrastructure of cell membranes and their derivatives. In The Structure and Function of Sub-Cellular Components. Ed. by E. M. Cook., p. 3. Cambridge University Press.

SMITH, T. \& 'TAYLOR, M. S. (1919). Some morphological and biological characters of the Spirilla (Vibrio fetus n.sp.) associated with disease of the fetal membranes in cattle. J. exp. Med. 30, 299.

TAKagi, A. \& Asaki, K. (1960). Electron microscopic observation on the origin of the flagella of a certain water Vibrio. Yonago Acta med. 4, 147.

Thornley, M. J. \& Horne, R. W. (1962). Electron microscope observations on the structure of fimbriae, with particular reference to Klebsiella strains, by the use of the negative staining technique. J. gen. Microbiol. 28, 51 .

van Bruggen, E. F. J., Wiebenga, R. H. \& Gruber, M. (1960). Negative-staining electron microscopy of proteins at $\mathrm{pH}$ values below their isoelectric points. Its application to hemocyanin. Biochim. biophys. Acta, 42, 171.

vaN ITERSON, W. (1947). Some electron-microscopical observations on bacterial cytology. Biochim. biophys. Acta, 1, 527.

Weidel, W., Frank, H. \& Leutgeb, W. (1963). Autolytic enzymes as a source of error in the preparation and study of Gram-negative cell walls. J. gen. Microbiol. 30, 127.

Werner, H. J. (1963). Further electron microscopic observations of a strain of Vibrio fetus. Am. J. Vet. Res. 24, 881.

Werner, H. J., Levy. H. \& Spurlock, B. O. (1961). Electron microscopic observations of a mucoid strain of Vibrio fetus. Am. J. Vet. Res. 22, 1121.

ZwILlENBerg, L. O. (1964). Electron microscopic features of Gram-negative and Grampositive bacteria embedded in phosphotungstate. Antonie van Leeureenhoek. 30, 154.

\section{EXPLANATION OF PLATES}

Plate 1

Fig. 1. Vibrio fetus (isolate no. 437) palladium shadowed. $\times 23,000$.

Fig. 2. Vibrio fetus (isolate no. 436) in potassium phosphotungstate negative stain. Note two types of organism distinguished by the condition of the cytoplasm. $\times 14,000$.

\section{Plate 2}

Fig. 3. Vibrio fetus (isolate no. 671) in potassium phosphotungstate negative stain. $\times 16,000$.

Fig. 4. Vibrio fetus (isolate no. 671) in potassium phosphotungstate negative stain. Terminal portion only, with five flagella. $\times 40,000$.

Fig. 5. Vibrio fetus (isolate no. 653) in potassium phosphotungstate negative stain. Intact multiply flagellated 'sport' with medial cleft (arrow). $\times 14,000$.

Fig. 6. Vibrio fetus (isolate no. 652) in potassium phosphotungstate negative stain. Plasmolysed organism illustrating flagellar attachments at the integument and retracted cytoplasm. $\times 85,000$.

Fig. 7. Vibrio fetus (isolate no. 436) in potassium phosphotungstate negative stain. Terminal portion of Mickle-treated organism. Note independent basal granules within the cytoplasm (arrows). $\times 170,000$. 
Plate 3

Fig. 8. Vibrio fetus (isolate no. 652) in uranyl acetate negative stain. Printed in bas-relief. Note the absence of a flagellar stub on cell displaying clumped cytoplasmic contents. $\times 110,000$.

Fig. 9. Vibrio fetus (isolate no. 4993) in potassium phosphotungstate negative stain. Note large spherical body in the flagellated pole (arrow) and cytoplasmic organization outlined by clefts

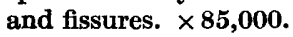

Fig. 10. Vibrio fetus (isolate no. 436) in uranyl acetate negative stain. Large spherical body has displaced the cytoplasmic contents at the pole. $\times 110,000$.

\section{Plate 4}

Fig. 11. Cellular residue of Vibrio fetus (isolate no. 436) after freeze and thaw cycle, in potassium phosphotungstate negative stain. Two membranous sacs are present : inner sac is coarsely matted and is without evidence of flagellar attachment, outer sac displays evidence of flagellar attachment but no geometrical pattern of a macromolecular structure. The outer sac has retained its curvature. $\times 110,000$.

Fig. 12. Liberated flagellum of Vibrio fetus (isolate no. 652) in potassium phosphotungstate negative stain. Proximal end is bent and inserted into the remnant of its basal granule. Only the distal tip shows evidence of a central core (arrow). $\times 85,000$.

Fig. 13. Broken flagellum of Vibrio fetus (isolate no. 436) in potassium phosphotungstate negative stain illustrating jagged ends. $\times 300,000$.

Fig. 14. Enlargement of the central portion of the flagellum of Vibrio fetus (isolate no. 652) shown in fig. 12. Parallel stranded structure is suggested. $\times \mathbf{3 4 0 , 0 0 0}$.

\section{Plate 5}

Fig. 15. Thin section of Vibrio fetus (isolate no. 436) embedded in divinylbenzene cross-linked methacrylates. Longitudinal aspect of a dividing S-shaped organism exhibiting rugose integument, compact fibrillar cytoplasm, rarefied polar regon, diffuse nucleoplasm, inclusions, basal granule and flagella stub. Segments of the complex cytoplasmic membrane appear at the flagellated pole and at the region of constriction separating the sister cells (arrows). $\times 140,000$.

Fig. 15 a. Enlargement of one terminus of the Vibrio fetus (isolate no. 436) organism shown in fig. 15 illustrating multilaminate and diffuse appearance of the integument except over the pole. Note the triangular profile of the basal granule (arrow). A fine-textured region of oval profile (S) is seen lying between the diffuse nucleoplasm and the rarefied polar region. This region is assumed to represent the large spherical bodies observed in negative stained organisms. $\times 210,000$.

Fig. 16. Ultrathin section of Vibrio fetus (isolate no. 436) embedded in divinylbenzene cross-linked methacrylates. Longitudinal aspect of a non-dividing S-shaped organism displaying cytoplasmic inclusions and globular or looped formations in the integument. $\times 110,000$.

Fig. 16a. Enlargement of a portion of the Vibrio fetus (isolate no. 436) organism shown in fig. 16 illustrating two types of inclusions, $(J)$ and $(G)$. Note the similarity between the integument and the cytoplasmic membrane. Thinness of the section precluded observation of the short bar-like elaborations associated with the complex cytoplasmic membrane. $\times 240,000$.

\section{Plate 6}

Fig. 17. Thin section of Vibrio fetus (isolate no. 436) embedded in divinylbenzene cross-linked methacrylates. Longitudinal aspect of the terminal portion of a comma-shaped organism, illustrating a segment of the complex cytoplasmic membrane at a lateral position (arrow). Note additional electron scatter contributed by the basal granule in the space lying between the integument and the cytoplasmic membrane. Depression of the integument at the region of flagellar insertion suggests its attachment to the basal granule. $\times 260,000$.

Fig. 18. Thin section of Vibrio fetus (isolate no. 436) embedded in divinylbenzene cross-linked methacrylates. Transverse aspect illustrating circumscription of the protoplasmic mass by the complex cytoplasmic membrane. Note the scalloped appearance of the inner boundary of the complex cytoplasmic membrane. $\times \mathbf{3 5 0 , 0 0 0}$.

Fig. 19. Thin section of Vibrio fetus (isolate no. 436) embedded in divinylbenzene cross-linked methacrylates. Cell pole and the proximal end of its detached flagellum are illustrated; note the thickened portion of the flagellum and its rounded tip. $\times 340,000$. 

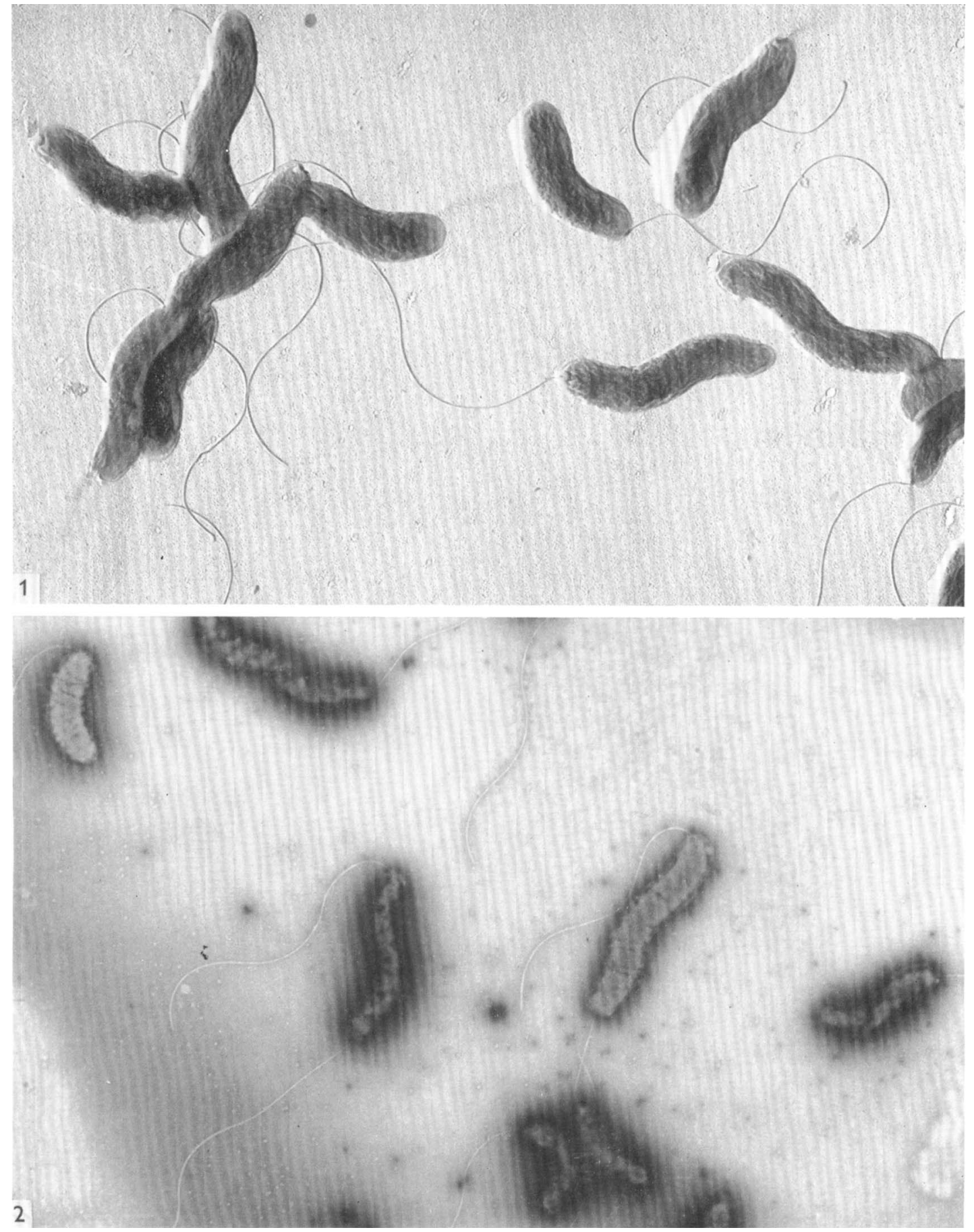

A. E. RITCHIE, R. F. KEELER AND J. H. BRYNER 

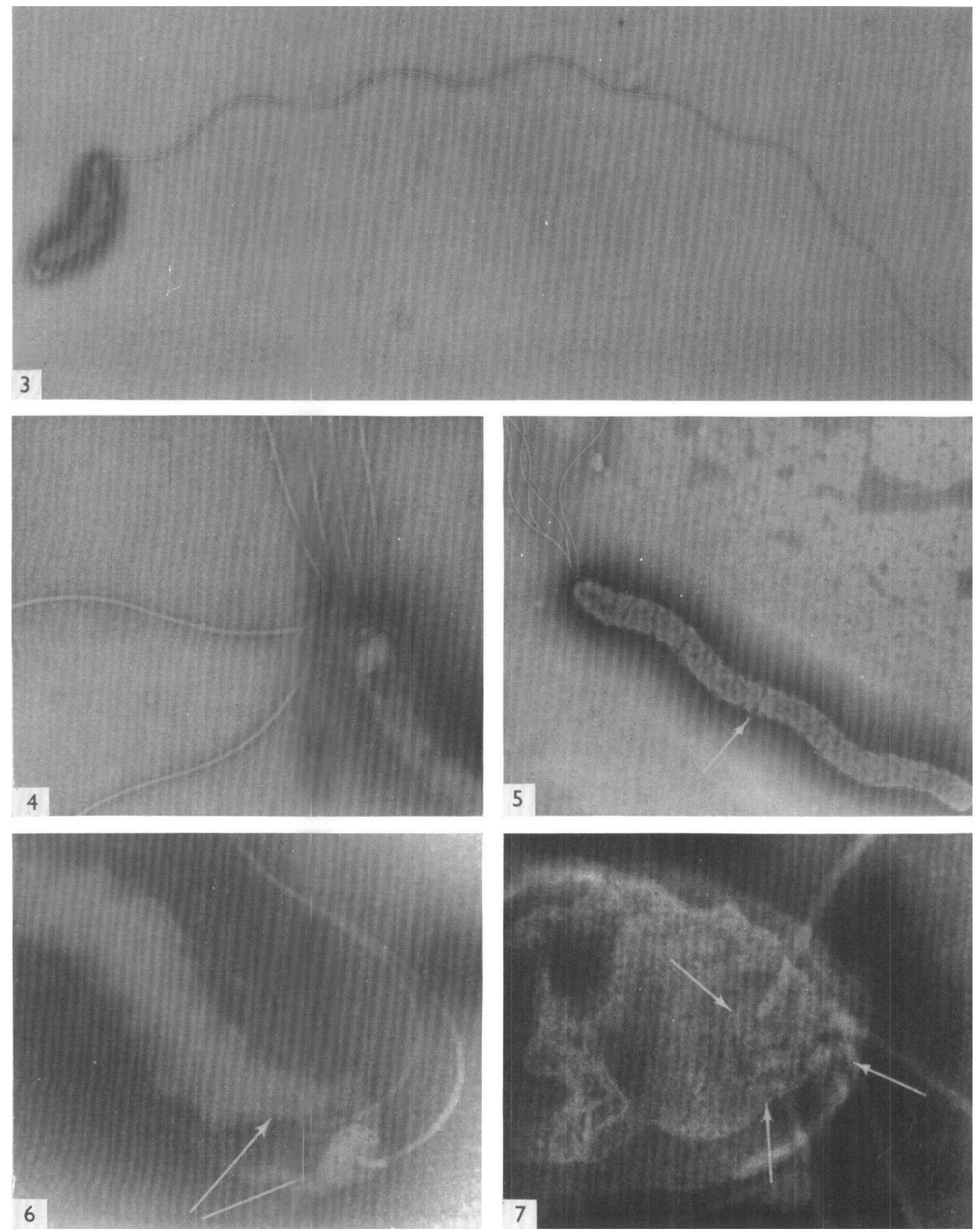

A. E. RITCHIE, R. F. KEELER AND J. H. BRYNER 
Journal of General Microbiology, Vol. 43, No. 3

Plate 3
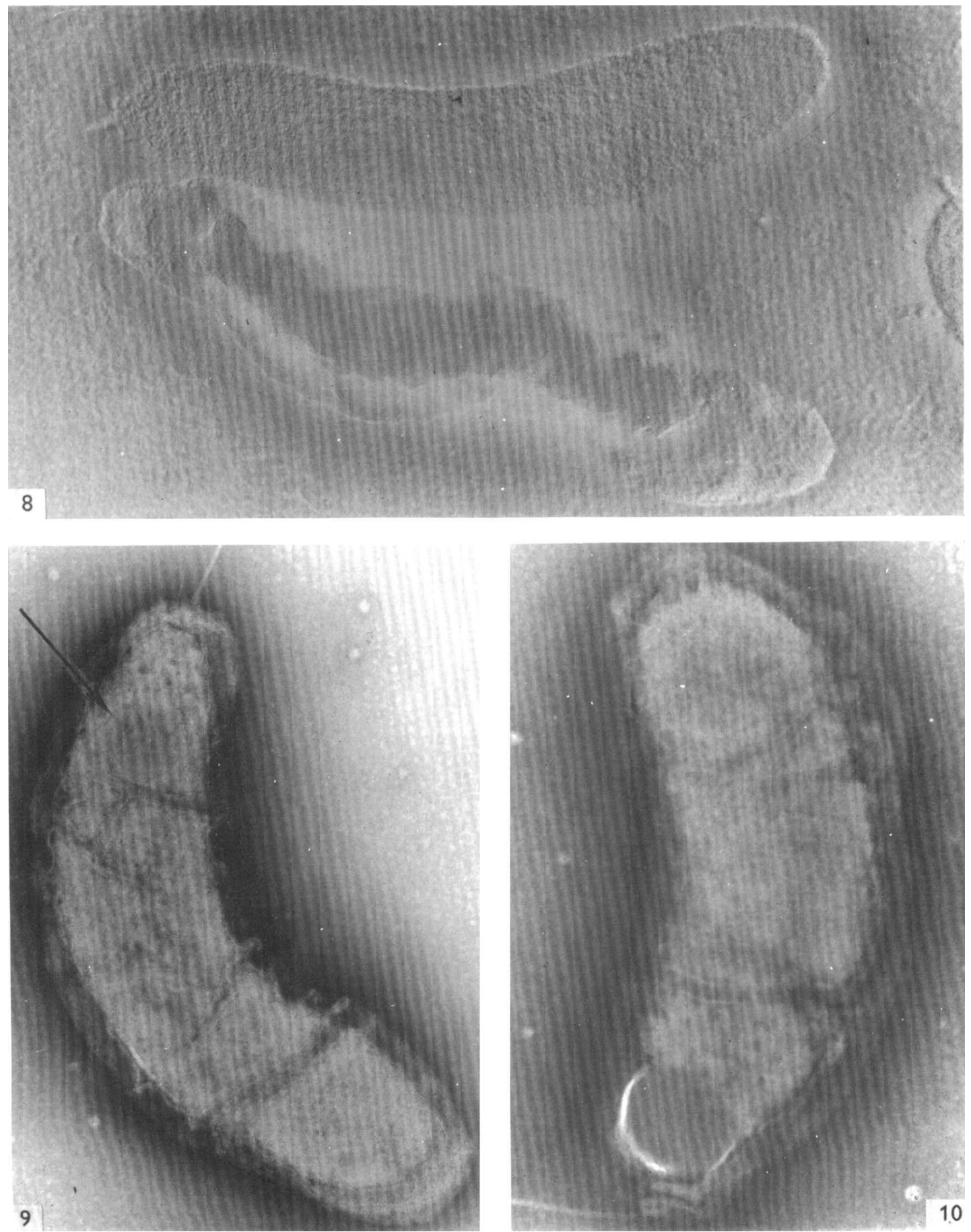

A, E. RITCHIE, R. F, KEELER AND J. H. BRYNER 
Journal of General Microbiology, Vol. 43, No. 3

Plate 4
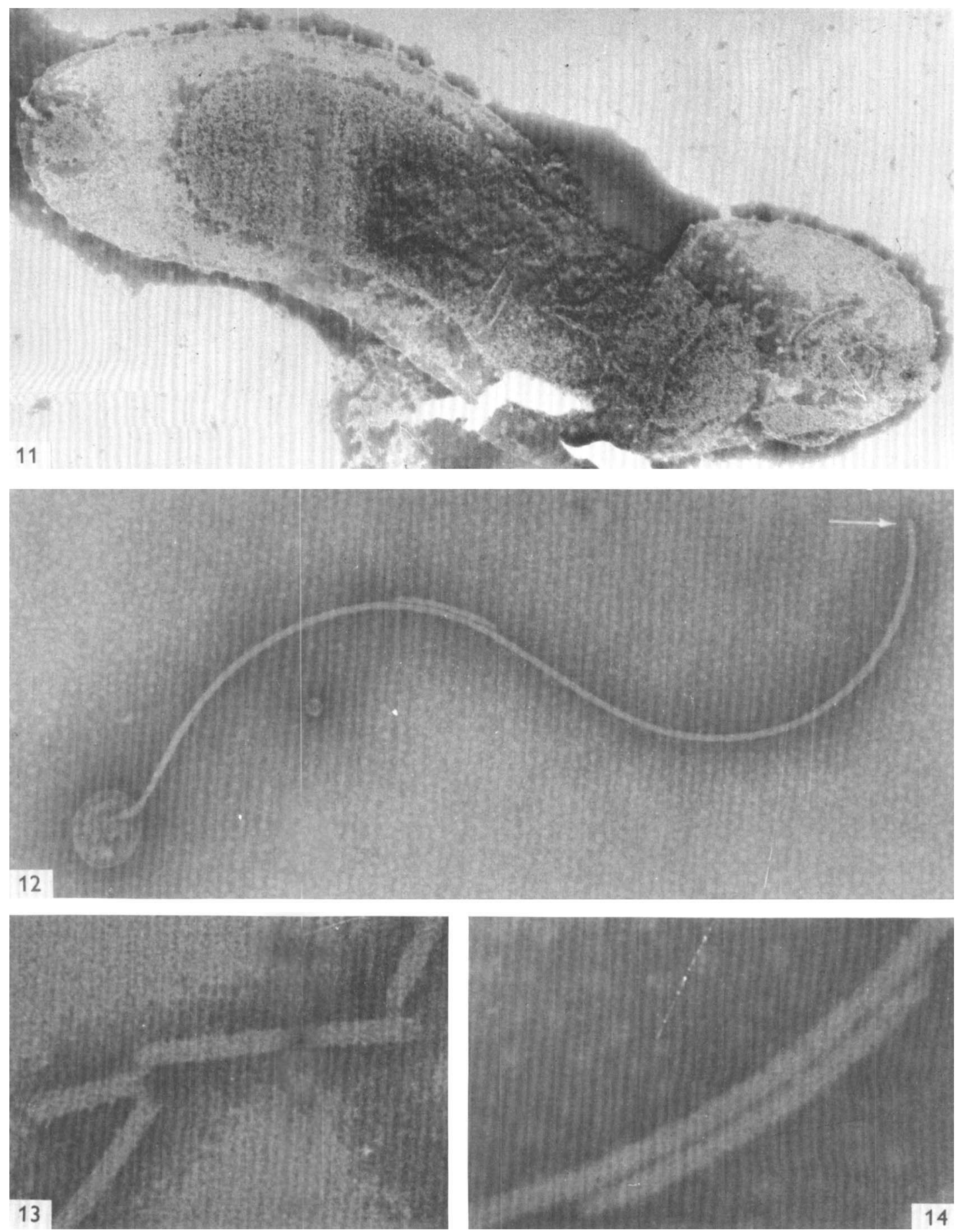

A. E. RITCHIE, R. F. KEELER AND J, H, BRYNER 
Journal of General Microbiology, Vol. 43, No. 3

Plate 5
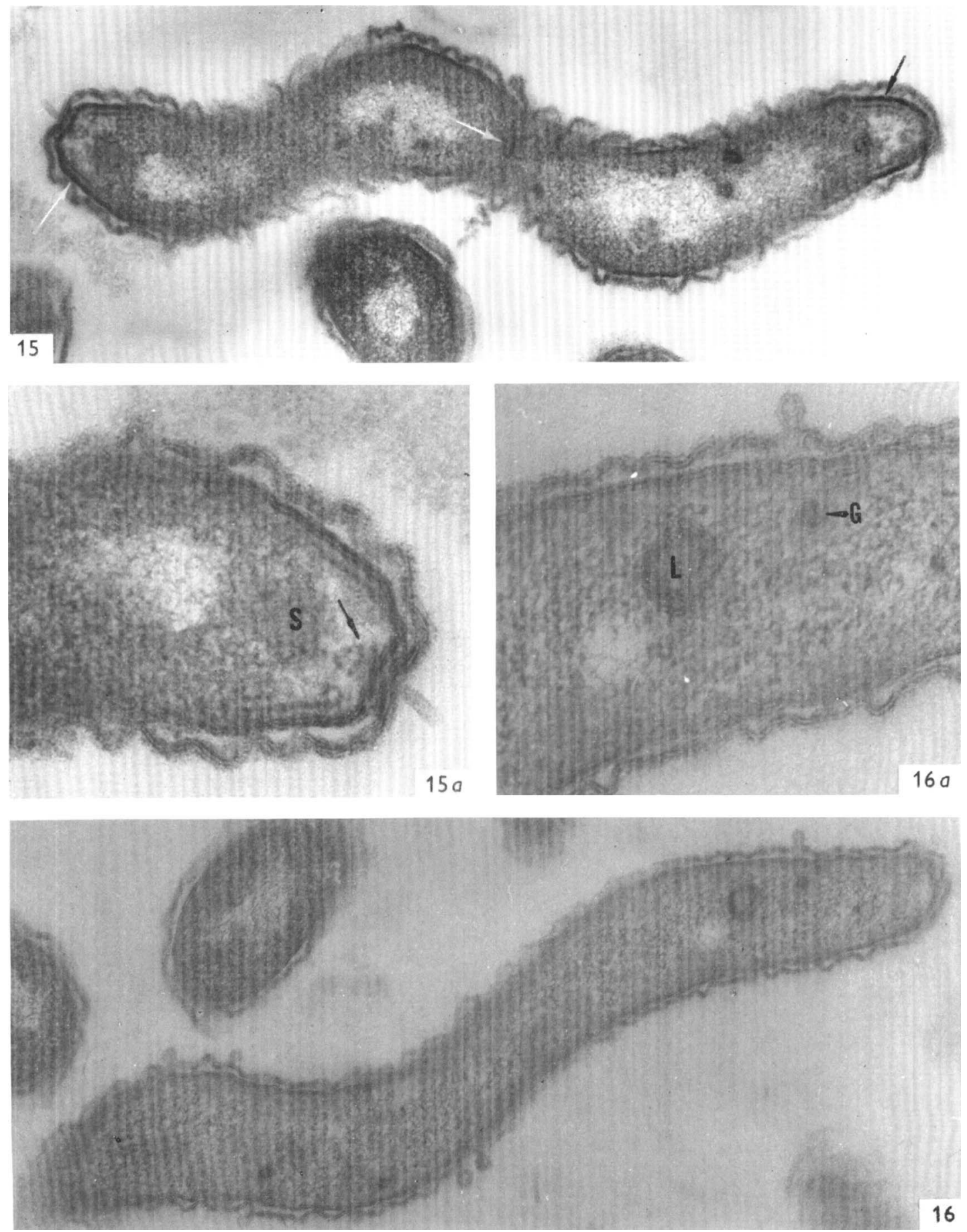

A. E. RITCHIE, R. F. KEELER AND J. H. BRYNER 

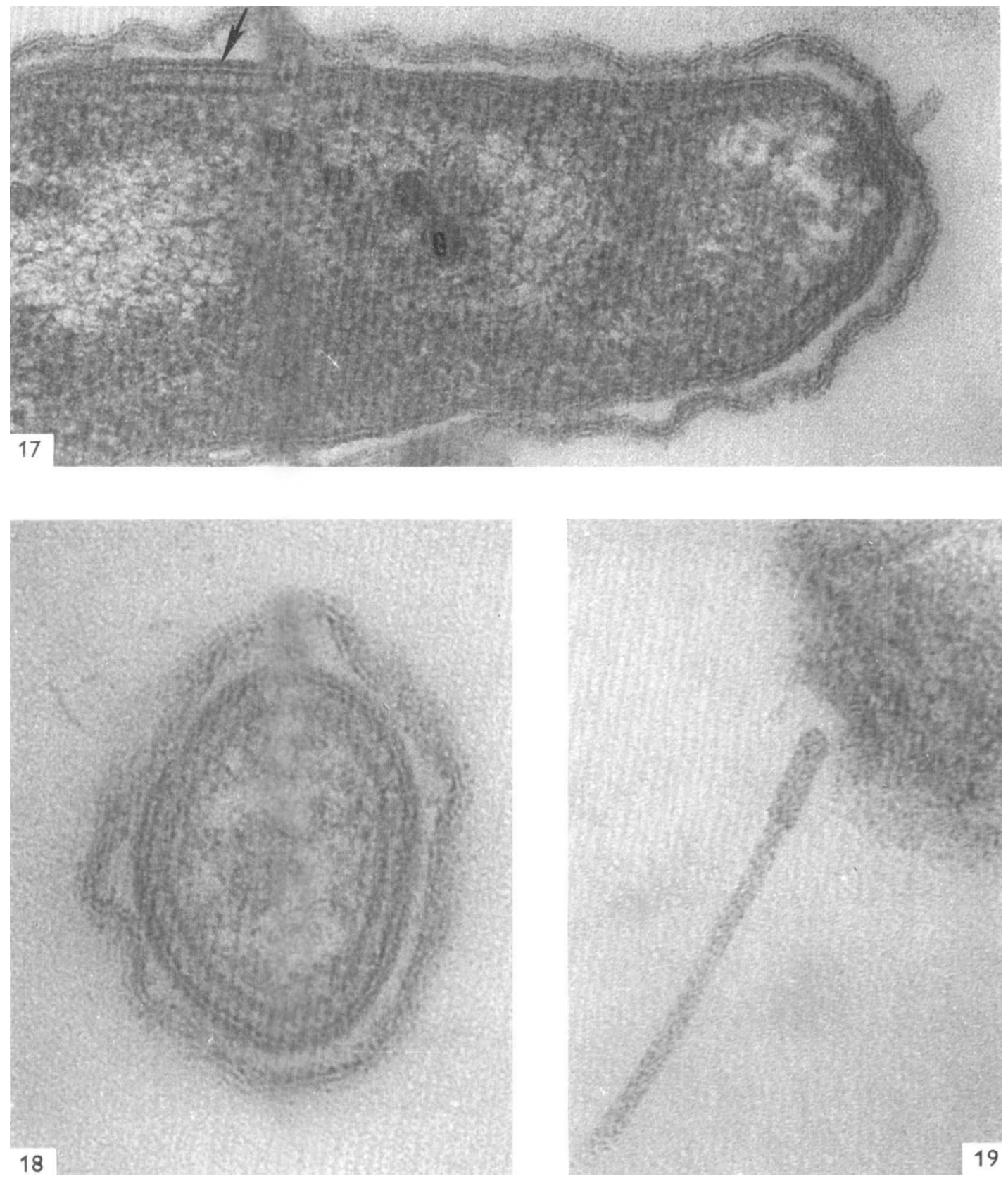

A. E. RITCHIE, R. F, KEELER AND J, H, BRYNER 